\title{
Understanding the Chemistry of Lead at a Molecular Level: The Pb(II) 6s6p Lone Pair Can Be Bisdirected in Proteins
}

\author{
Marie-Céline Van Severen, ${ }^{*}{ }^{\S}$ Ulf Ryde, ${ }^{\ddagger}$ Olivier Parisel, ${ }^{\dagger}$ and Jean-Philip Piquemal ${ }^{\dagger}$ \\ ${ }^{\dagger}$ Laboratoire de Chimie Théorique, UPMC, CC 137, 4 place Jussieu, 75252 Paris, Cedex 05, France and CNRS, UMR 7616, CC 137, \\ 4 place Jussieu, 75252, Paris Cedex 05, France \\ ${ }^{\ddagger}$ Theoretical Chemistry, Lund University, P.O. Box 124, 22100 Lund, Sweden \\ ${ }^{\S}$ Department of Chemistry - Ångström Laboratory, Theoretical Chemistry, Uppsala University, Sweden
}

ABSTRACT: $\mathrm{Pb}^{2+}$ complexes can attain several different topologies, depending of the shape of the $\mathrm{Pb} 6 s 6 \mathrm{p}$ lone pair. In this paper, we study structures with a bisdirected $\mathrm{Pb}$ lone pair with quantum mechanics (DFT) and QM/MM calculations. We study small symmetric $\mathrm{Pb}^{2+}$ models to see what factors are needed to get a bisdirected lone pair. Two important mechanisms have been found: First, the repulsion of the lone pair of $\mathrm{Pb}^{2+}$ with other lone pairs in the equatorial plane leads to a bisdirected structure. Second, a bisdirected lone pair can also arise due to interactions with double bonds, lone pairs, or hydrogen atoms. Moreover, we have analyzed $\mathrm{Pb}^{2+}$ sites in proteins and to see if a bisdirected lone pair can exist in an asymmetrical environment. Several instances of bisdirected lone pairs were discovered.

\section{INTRODUCTION}

The toxicity of lead has been known since antiquity, and for mammals its ingestion results in the well-known disease saturnism. Experiments indicate that two types of $\mathrm{Pb}^{2+}$ complexes exist: holo- and hemidirected organizations (see Figure 1). ${ }^{1}$ This structural difference is caused by the peculiar capably of the $\mathrm{Pb} 6 \mathrm{~s} 6 \mathrm{p}$ lone pair to adapt to the presence of ligands. ${ }^{2}$ Hemidirected complexes arise when $\mathrm{Pb}^{2+}$ has ligands in one hemisphere, letting the lone pair expand in the opposite direction. This extension of the lone pair can cause structural variations in protein chelation sites and perturbs its native structure, leading to the possible loss of activity. ${ }^{3}$ When this is

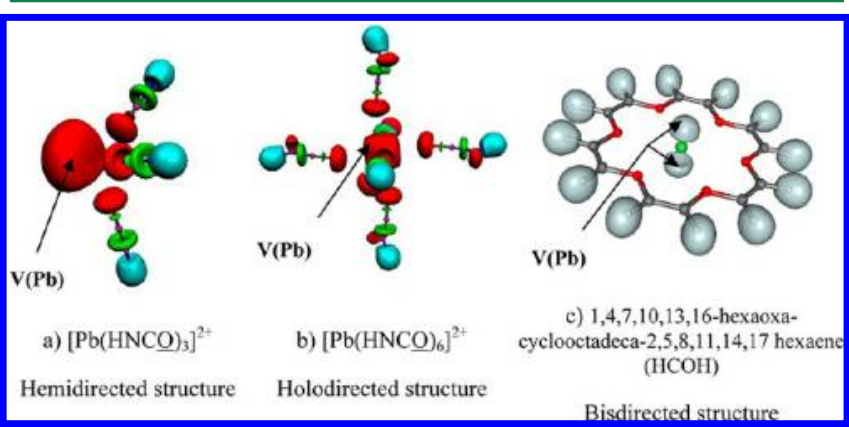

Figure 1. Three different topological structures of the lone pair of $\mathrm{Pb}^{2+}$. The red color is used for a basin that belongs to only one atom. The green color is used for basin shared by two atoms, and the blue color is for the hydrogen + the covalent bond $\mathrm{H}-\mathrm{X}$ with $\mathrm{X}=$ any atoms. On the righ, $\mathrm{t}$ the basin of $\mathrm{Pb}^{2+}$ and the basin of $\mathrm{H}$ are not colored. not possible, due to strong steric and electrostatic interactions between the ligands, holodirectional complexes are recovered, and the lone pair loses its stereochemical activity.

In a recent paper, we showed that the lone-pair organization can be even more complex: We observed a third possible organization of the $6 \mathrm{~s} 6 \mathrm{p}$ lone pair, called bisdirected ${ }^{4}$ (see Figure 1c). In this case, the lone pair is split in two hemispheres. Such a topological structure was obtained when $\mathrm{Pb}$ was bound to a plane and symmetric molecule. In this study, we investigate when the lone pair of $\mathrm{Pb}^{2+}$ will be bisdirected, what factors favor this structure, if such a topological structure could exist within proteins where the symmetry and flatness are absent. To address such issues, we analyze the behavior of the lone pair of $\mathrm{Pb}^{2+}$ in different environments using the electron localization function (ELF) analysis to visualize the extension of the lone pair and natural bond orbital (NBO) to find the corresponding atomic occupations.

\section{RESULTS}

In this article, we will study bisdirected $\mathrm{Pb}^{2+} 6 \mathrm{~s} 6 \mathrm{p}$ lone pairs in various structures. We use the topological analysis method ELF because it is a powerful tool to localize and visualize regions in the space where electrons are the most or less localized based on the excess of kinetic energy of the electrons compared to a homogenized gas of electrons. This gives rise to basins that show excess of electrons like lone pairs or bonds. Those basins are defined by an isosurface (with a value between 0 and 1).

Received: June 23, 2012

Published: April 9, 2013 


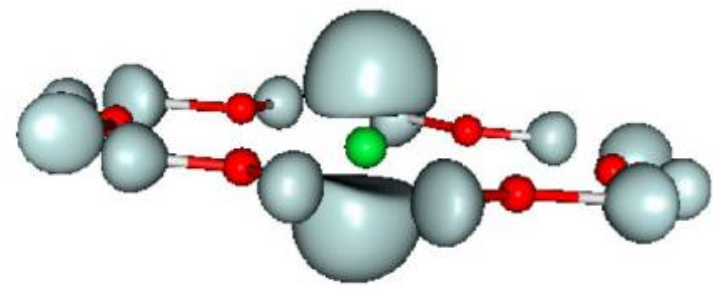

a) Hydrogens of $\mathrm{H}_{2} \mathrm{O}$ are in the plane of the molecule

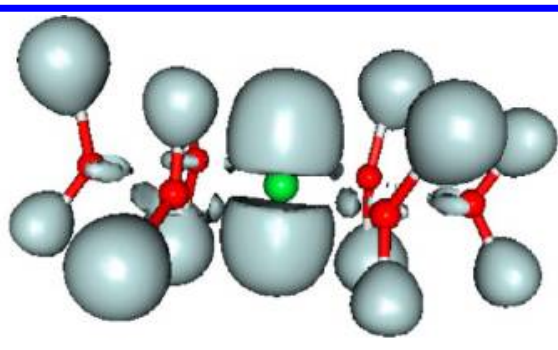

b) Hydrogens of $\mathrm{H}_{2} \mathrm{O}$ are out of the plane of the molecule

Figure 2. ELF representation of 1,4,7,10,13,16-hexaoxa-cyclooctadeca-2,5,8,11,14,17 hexaene ( $\mathrm{HCOH}$ ) replaced by six water molecules with the same position of the oxygens as in $\mathrm{HCOH}$.

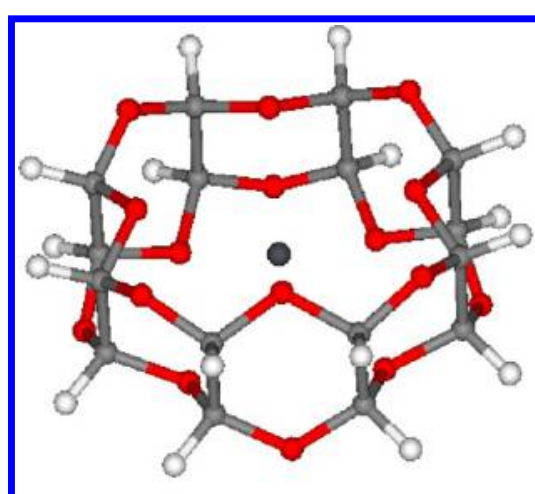

a) Ball and stick representation

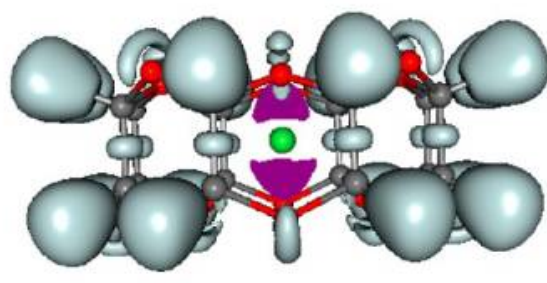

b) Side view

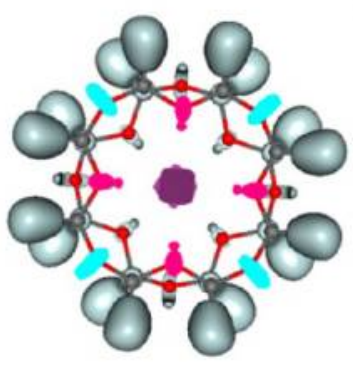

c) Top view

Figure 3. Schematic and ELF representations of complex A. Violet color is for the basin of $\mathrm{Pb}^{2+}$, the pink color for the basin of the oxygens that point inside the cycle, and the blue color for the basin of oxygens that point outside the cycle.

The higher it is, the thinner the basin is. For instance, if the value of the isosurface is 0 , then there will be a big basin including the entire molecule, with no details on what kind of bonds or lone pair there is in this molecule. If the isosurface is 0.8 , for example, then all the lone pairs and the bonds will be visible by their corresponding basins. And at 1, there are no basins left. So in particular ELF can show the basin corresponding to the valence lone pair of $\mathrm{Pb}^{2+}$ called $\mathrm{V}(\mathrm{Pb})$. In this study, all the isosurfaces are taken at 0.8 , except when specified. First, we study series of nonexistent molecules designed to have special features in order to get some insight on the structure and the composition of ligands that give rise to the bisdirected structure. Those molecules are symmetric, but we are interested in asymmetric environment as well. Second, we focus on protein systems coming from a PDB structure where we kept only a few atoms around $\mathrm{Pb}^{2+}$. No optimization of our systems at this stage has been done because the only information wanted at this stage of the study is to know if the bisdirected structure can exist in a system where the atoms are in a "random" way around $\mathrm{Pb}^{2+}$. Third, we use more advance methods ( $\mathrm{MD}$ and $\mathrm{QM} / \mathrm{MM}$ calculations) in a protein environment to see if this structure still exists.

Bisdirected Lone Pairs in Model Complexes. Here, we will focus on four different complexes and their derived complexes: 1,4,7,10,13,16-hexaoxa-cyclooctadeca-2,5,8,11,14,17 hexaene $(\mathrm{HCOH})$ in Figure $1 \mathrm{c}$, the $\mathrm{Pb}\left(\mathrm{C}_{16} \mathrm{H}_{16} \mathrm{O}_{16}\right)^{2+}$ complex (complex A) in Figure $3, \mathrm{~Pb}\left(\mathrm{C}_{18} \mathrm{H}_{24}\right)^{2+}$ complex (complex B) in Figure 8, and a tested series of cyclic ligands constructed from merged benzene rings.

The first time the bisdirected structure was observed was in the system shown in the Figure 1c. This chelating ligand
$\mathrm{HCOH}$ consists of six oxygen atoms alternating with six $\mathrm{C}=\mathrm{C}$ double bonds. To understand if the shape of the lone pair of $\mathrm{Pb}^{2+}$ is induced by the oxygens or the double bonds, we have designed the systems shown in Figure 2. We kept the same place for the oxygens as in the $\mathrm{HCOH}$ system, but we deleted the double bonds and replaced the carbon atoms with hydrogen atoms. Thus, the complex is now formed by six water molecules with the oxygen atoms located in the same place as the oxygen atoms in $\mathrm{HCOH}$ in Figure 1c.

From the ELF analysis in Figure 3a, it is obvious that the lone pair of $\mathrm{Pb}^{2+}$ is still bisdirected. It seems that this structure is caused by the repulsion of the lone pairs of oxygen atoms. To exclude the possibility that the bisdirected structure is linked to the direction of the water molecules, another calculation was carried out with the hydrogen atoms directed vertically to plane with the $\mathrm{Pb}$ and $\mathrm{O}$ atoms (see Figure $3 \mathrm{~b}$ ). However, the ELF analysis shows that the lone pair of $\mathrm{Pb}^{2+}$ is still bisdirected. This indicates that the $\mathrm{Pb}^{2+}$ lone pair will be bisdirected in structures where some atoms induce repulsion in a plane.

A NBO (Natural Bond Orbital) analysis has been carried out to detect any difference in the population in the $\mathrm{p}$ orbitals of $\mathrm{Pb}^{2+}$ in those systems. Table 1 shows electronic populations of the donor orbitals: $2 \mathrm{p}$ of $\mathrm{O}$ and $1 \mathrm{~s}$ of $\mathrm{H}$ and the acceptor $6 \mathrm{p}$ orbitals of $\mathrm{Pb}^{2+}$.

As the $6 \mathrm{~s}$ of $\mathrm{Pb}^{2+}$ is already full, the occupation of $6 \mathrm{p}$ orbitals is important because they will receive the electron for the environment. It can be seen that the lone pair of $\mathrm{Pb}^{2+}$ in the $\mathrm{HCOH}$ complex has a higher population than in the complexes with water molecules. The oxygen orbitals of this complex have lower populations than the water complexes because of the more polar bonds in the water molecules. 
Table 1. NBO Analysis of the Bisdirected Structures in Figures 2 and 3 for Only One Oxygen and One Hydrogen in the Different System

\begin{tabular}{lccc}
\multicolumn{1}{c}{ ligand } & $\mathrm{Pb}(\mathrm{p})$ & $\mathrm{O}(\mathrm{p})$ & $\mathrm{H}(\mathrm{s})$ \\
$\mathrm{HCOH}$ (see Figure 1c) & 0.50 & 4.96 & 0.73 \\
$\left(\mathrm{H}_{2} \mathrm{O}\right)_{6}$ planar (see Figure 2a) & 0.19 & 5.27 & 0.45 \\
$\left(\mathrm{H}_{2} \mathrm{O}\right)_{6}$ perpendicular hydrogens (Figure 2b) & 0.22 & 5.32 & 0.40 \\
\hline
\end{tabular}

This example is not enough to settle why the bisdirected structure is observed. Further evidence can be obtained by using a second molecule that is of toroidal shape. Therefore, we studied the $\mathrm{Pb}\left(\mathrm{C}_{16} \mathrm{H}_{16} \mathrm{O}_{16}\right)^{2+}$ complex (complex A) in Figure 3. In this new system, the oxygen atoms are placed in planes that are under and above $\mathrm{Pb}^{2+}$.

As can be seen from the ELF analysis, again the lone pair of $\mathrm{Pb}^{2+}$ is bisdirected. From Figure $4 \mathrm{~b}$, it can be seen that the ELFs form three planes, two formed by alternation of the oxygen and carbon atoms on the top and bottom of the ligand and a third one, in the middle of the ligand, formed by the C$\mathrm{C} \sigma$ bonds. The bisdirected lone pair can be caused by two effects, viz., either the alignment of the lone pair of $\mathrm{Pb}^{2+}$ with the lone pairs of the oxygen atoms or the repulsion from the $\sigma$ bonds. In Figure 3c, we have color-coded the oxygen lone pairs depending on whether they point toward the $\mathrm{Pb}$ ion (pink) or out of the molecule (blue). This shows that the blue oxygen lone pairs do not interact with the lone pair of $\mathrm{Pb}^{2+}$, because they point to the outside the molecule, whereas the pink oxygen lone pairs interact with the bisdirected lone pair on $\mathrm{Pb}^{2+}$.

To further understand this phenomenon, the ligand was simplified in a similar manner as for the $\mathrm{HCOH}$ complex above, keeping only the eight pink oxygen atoms. An ELF analysis of the remaining $\mathrm{Pb}\left(\mathrm{H}_{2} \mathrm{O}\right)_{8}$ complex (complex A2) was performed without any optimization of the structure. The results in the Figure 4 show that a bisdirected lone pair is still found. This indicates that the electronic shape is caused by the oxygen atoms and not by the $\sigma$ moiety.

In our previous study, however, we found that a fully optimized $\left[\mathrm{Pb}\left(\mathrm{H}_{2} \mathrm{O}\right)_{8}\right]^{2+}$ complex gave rise to a holodirected structure $^{5}$ (see Figure 5). Comparing Figures 4 and 5, it can be

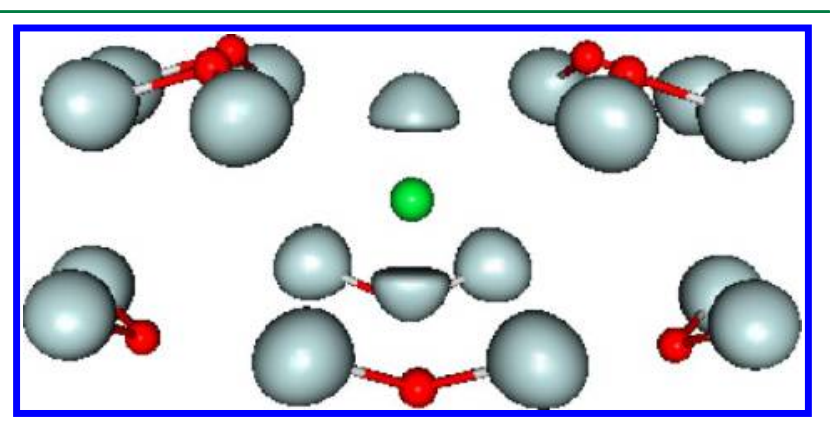

Figure 4. $\mathrm{Pb}\left(\mathrm{H}_{2} \mathrm{O}\right)_{8}$ with oxygens atoms in the same positions as in complex A: complex A2. The value of the isosurface is 0.9 , showing a bisdirected lone pair.

noted that the positions of the hydrogen atoms are different. Therefore, another ELF analysis was carried out after moving the hydrogen atoms in the same way as in Figure 4, keeping the oxygen atoms at their optimized positions. Despite this structural change the results in Figure 6 show that the lone pair of $\mathrm{Pb}^{2+}$ is still holodirected.

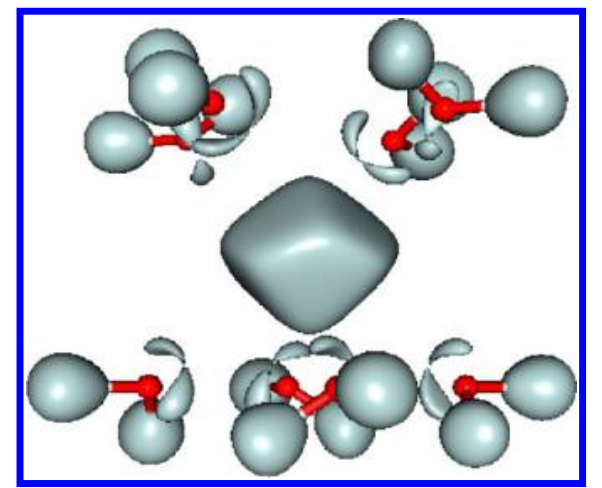

Figure 5. ELF representation of the optimized structure of $\left[\mathrm{Pb}\left(\mathrm{H}_{2} \mathrm{O}\right)_{8}\right]^{2+}$. The lone pair of $\mathrm{Pb}(\mathrm{II})$ is holodirected.

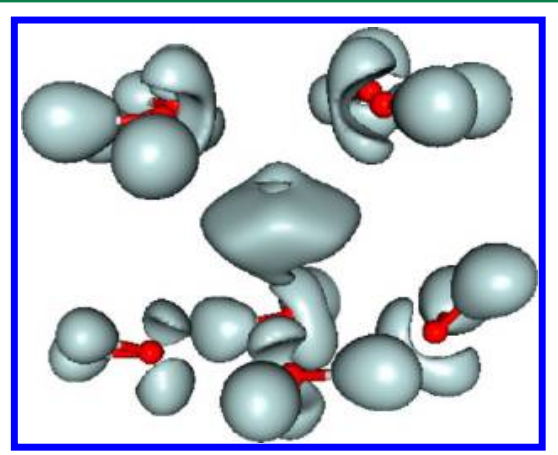

Figure 6. ELF representation of $\left[\mathrm{Pb}\left(\mathrm{H}_{2} \mathrm{O}\right)_{8}\right]^{2+}$ with the hydrogen atoms oriented in the same way as in the complex A2. The value of the isosurface is 0.7 and shows a lone pair of $\mathrm{Pb}$ (II) that is holodirected.

In fact, there is still another difference between Figures 4 and 5 , viz., the $\mathrm{O} 1-\mathrm{Pb}-\mathrm{O} 2$ angle, where $\mathrm{O} 1$ is the oxygen of the top plane and $\mathrm{O} 2$ is the oxygen of the bottom plane. In the structure in Figure 4, this angle is $70^{\circ}$, whereas it is $92^{\circ}$ for the structure in Figure 5. Therefore, we keep the structure of Figure 4 and increase the angle, still without any optimization. From the ELF analysis in Figure 7, it can be seen that at $72^{\circ}$, the structure is still bisdirected. However, at $78^{\circ}$, the $\mathrm{Pb}^{2+}$ lone pair starts to become a torus, in addition to being bisdirected. At $81^{\circ}$, we have clearly a torus and still a bisdirected structure. Finally at $89^{\circ}$, only a torus is observed. Thus, it seems that increasing the angle between the two planes induces a change

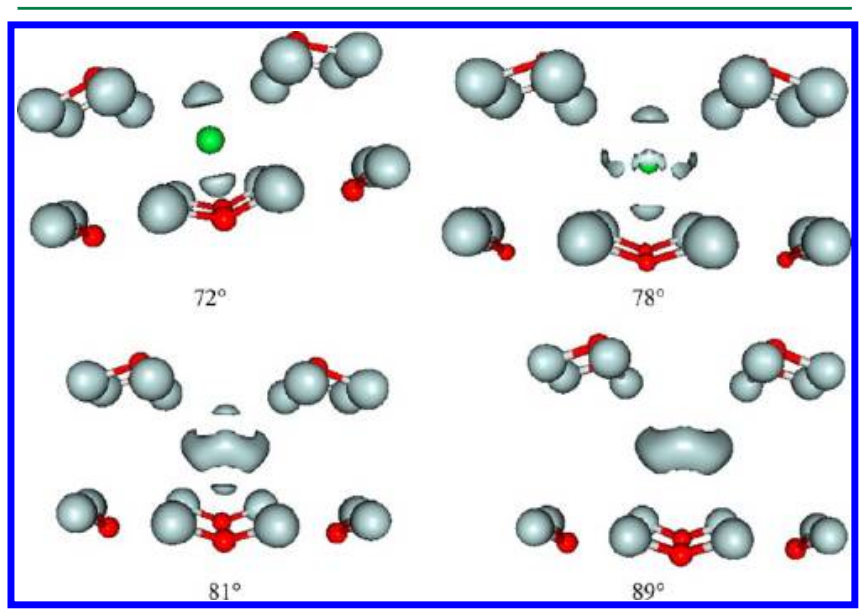

Figure 7. ELF analysis of complexes A2 with different values of the $\mathrm{O} 1-\mathrm{Pb}-\mathrm{O} 2$ angle. Isosurface value, 0.9 . 
in the interaction between oxygen and $\mathrm{Pb}^{2+}$ lone pairs. The variation of the $\mathrm{O} 1-\mathrm{Pb}-\mathrm{O} 2$ angle induces a change in the shape of the $\mathrm{Pb}^{2+}$ lone pair from bisdirected to a torus. Consequently, the formation of the bisdirected structure seems to be linked to the orientation of the oxygen lone pairs around the $\mathrm{Pb}^{2+}$ ion.

The NBO analysis of these complexes (see Table 2) shows an increased $\mathrm{Pb}^{2+}$ lone pair population with an increased $\mathrm{O} 1-$

Table 2. NBO Analysis and Relative Energies ( $\mathrm{kcal} / \mathrm{mol}$ ) of Complex A2, the $\mathrm{O} 1-\mathrm{Pb}-\mathrm{O} 2$ Angle Increasing

$\begin{array}{ccc}\mathrm{O} 1-\mathrm{Pb}-\mathrm{O} 2 \text { angle } & \mathrm{Pb} 6 \mathrm{p}^{-} & \text {energy } \\ 69^{\circ} & 0.36 & 28 \\ 72^{\circ} & 0.38 & 16 \\ 78^{\circ} & 0.40 & 1 \\ 81^{\circ} & 0.43 & 0 \\ 89^{\circ} & 0.44 & 10\end{array}$

$\mathrm{Pb}-\mathrm{O} 2$ angle. Likewise, the energies decrease with this angle, except for $89^{\circ}$, because the complexes are not optimized. For the optimized $\left[\mathrm{Pb}\left(\mathrm{H}_{2} \mathrm{O}\right)_{8}\right]^{2+}$ complex, the angle is $92^{\circ}$, and the energy is $94 \mathrm{kcal} / \mathrm{mol}$ lower than for the most stable complex in Table 2. Thus, the interactions between lead and the ligands become more and more important while the angle increases.

Next, we studied the effect of the $\pi$ bonds. First, we tested the $\mathrm{Pb}\left(\mathrm{C}_{18} \mathrm{H}_{24}\right)^{2+}$ complex (complex B) in Figure 8, which has

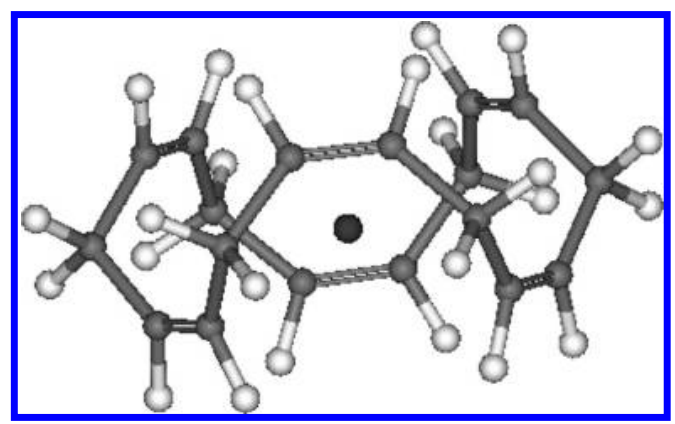

Figure 8. The $\mathrm{Pb}\left(\mathrm{C}_{18} \mathrm{H}_{24}\right)^{2+}$ complex (complex B).

three double bonds at the top and three double bonds at the bottom of the ligand. After optimization, $\mathrm{Pb}^{2+}$ is at the center of the chelate. An ELF analysis reveals that the structure is bisdirected (see Figure 9). Here, the carbon and $\mathrm{Pb}^{2+}$ lone pairs are aligned, but the $\sigma$ bonds of the $\mathrm{C}-\mathrm{C}$ bonds are aligned with the hole of the lone pair of $\mathrm{Pb}^{2+}$.

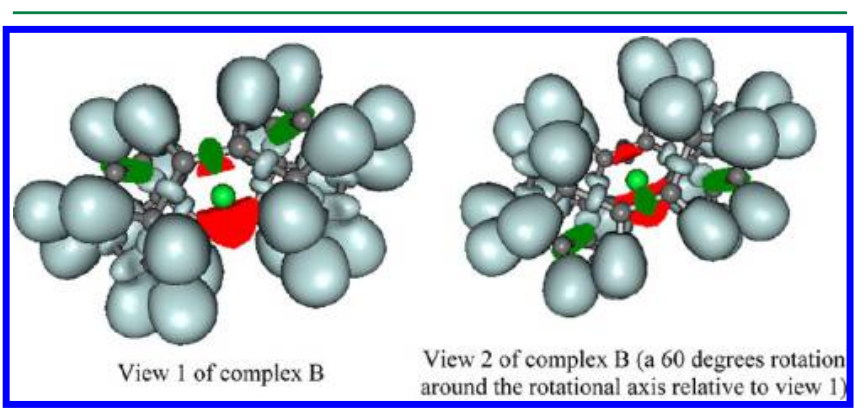

Figure 9. ELF representation of complex $\mathrm{B}$. The lone pair of $\mathrm{Pb}(\mathrm{II})$ is hemidirected. The basin of $\mathrm{Pb}^{2+}$ is in red and the basin of the $\pi$ bonds in green.
To know which of those phenomena is responsible for the bisdirected shape, additional calculations were run. First, we removed the $\sigma$ bonds, without any optimization. The ELF analysis in Figure 10 shows that the $\pi$ bonds are enough to give a bisdirected structure.

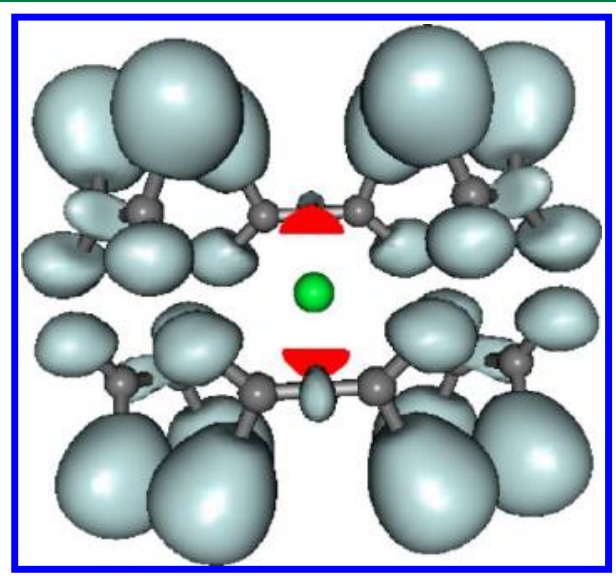

Figure 10. ELF representation of $\mathrm{Pb}^{2+}$ surrounded by six ethylene molecules.

Second, we removed the lower part of the ligand and kept only the upper part of it, i.e., $\mathrm{Pb}^{2+}$ and three ethylene molecules. The ELF analysis in Figure 11 shows that the hemidirected structure is obtained, which illustrates that ligands on both sides of the $\mathrm{Pb}^{2+}$ ion are needed to give a bisdirected structure.

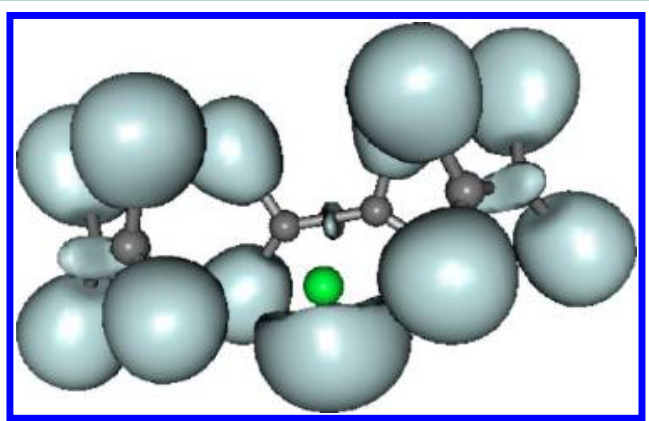

Figure 11. ELF representation of $\mathrm{Pb}^{2+}$ surrounded by three ethylene molecules. The lone pair of $\mathrm{Pb}(\mathrm{II})$ is hemidirected.

Next, we tested a series of cyclic ligands constructed from merged benzene rings. The aim was to see what happens when the symmetry is broken by removing some of the carbon atoms. The whole system is optimized. The left part of Figure 12 shows $\mathrm{Pb}^{2+}$ surrounded by eight merged benzene rings. The ELF analysis reveals that the lone pair of $\mathrm{Pb}^{2+}$ is split in three: two bisdirected lobes and a torus-shape central lobe. One can see a clear alignment between the lone pair of $\mathrm{Pb}^{2+}$ and the $\pi$ bonds of benzene.

However, if a pair of carbon atoms is saturated in one of the benzene molecules (Figure $12 \mathrm{~b}$ ), the $\mathrm{Pb}^{2+}$ lone pair becomes hemidirected, and the distance between $\mathrm{Pb}^{2+}$ and the two saturated carbons becomes shorter than the distances to the other carbon atoms.

Next, three benzenes have been removed, leaving only five benzene rings (Figure 13a). In Figure 13b, the two first carbons on each side of the molecule have been removed, and in Figure $13 \mathrm{c}$ the two next carbons on each side have been deleted. These 

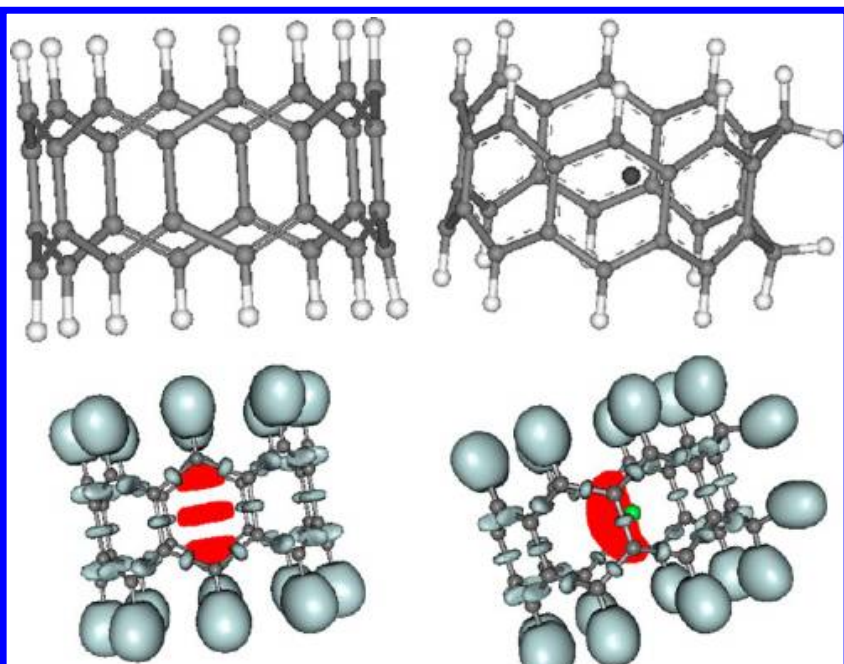

a) $\mathrm{Pb}\left(\mathrm{C}_{32} \mathrm{H}_{16}\right)^{2+}$

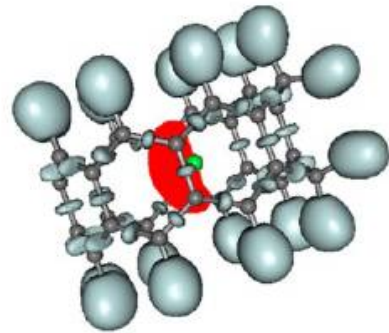

b) $\mathrm{Pb}\left(\mathrm{C}_{32} \mathrm{H}_{18}\right)^{2+}$

Figure 12. Schematic and ELF representations of the complex B and its corresponding hydrogenated form.

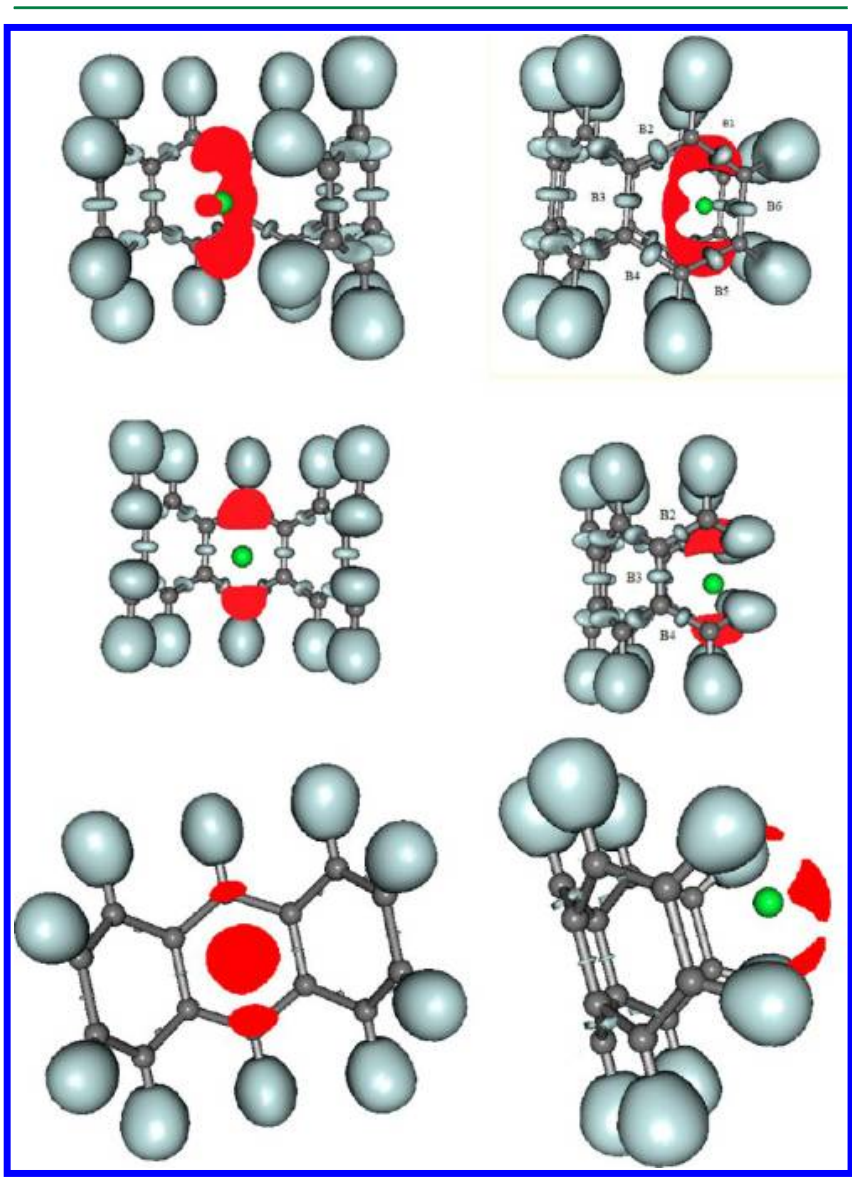

Figure 13. The complexes with cut merged benzene rings: (a) the top two pictures, $\mathrm{Pb}\left(\mathrm{C}_{22} \mathrm{H}_{14}\right)^{2+}$; (b) the middle two pictures, $\mathrm{Pb}$ $\left(\mathrm{C}_{18} \mathrm{H}_{14}\right)^{2+}$ with three intact benzene rings; and (c) the bottom two, $\mathrm{Pb}\left(\mathrm{C}_{14} \mathrm{H}_{10}\right)^{2+}$ also with three benzene rings.

systems are now opened, and no optimization has been done: the aim is just to see how the lone pair reacts in different environments. This was followed by an ELF analysis. The results in Figure 13a show that the lone pair of $\mathrm{Pb}^{2+}$ is vertically and horizontally bisdirected. The horizontal lone pair of $\mathrm{Pb}^{2+}$ is aligned with the $\pi$ bonds $\mathrm{B} 1$ and $\mathrm{B} 2$ on one side and B4 and B5 on the other. The vertical lone pair is aligned with $\mathrm{B} 3$ on one side and with $\mathrm{B} 6$ on the other.

Then, we removed two $\mathrm{C}$ atoms at each end of the ligand, giving three merged benzene rings with two $\mathrm{CH}_{2}$ groups at each end. As can be seen in Figure 14b, the lone pair of $\mathrm{Pb}^{2+}$ is only vertically bisdirected and aligned with B2 and B4.

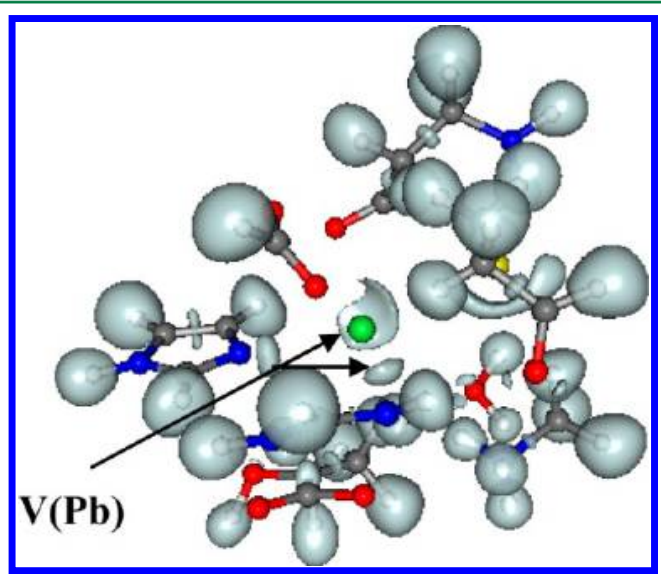

Figure 14. ELF analysis of $\mathrm{Pb}$ site 4 in the crystal structure of DAHPS (1QR7). $\mathrm{V}(\mathrm{Pb})$ is the ELF valence basin of $\mathrm{Pb}^{2+}$.

When the four $\mathrm{CH}_{2}$ groups are also removed (Figure 13c), a minority of the lone pair of $\mathrm{Pb}^{2+}$ is vertically bisdirected, whereas the majority of the lone pair is hemidirected. This time the lone pair of $\mathrm{Pb}^{2+}$ becomes bisdirected by interacting with the hydrogen atoms. It seems that the lone pair can be stabilized in its bisdirected structure due to hydrogen bond type interactions. The hemidirected structure is caused by the phenomenon shown in Figure 11: the necessity to have an interaction on each side of the lone pair. Indeed, in Figure 13a the lone pair is horizontally bisdirected, but in Figure 13c, the lone pair is hemidirected. This difference comes from the fact that in Figure 13a we have $\pi$ bonds on both sides of the lone pair and not in the $\mathrm{c}$ part.

So in this section, we found that a bisdirected structure can be obtained with oxygens atoms that are organized in planes below and above $\mathrm{Pb}^{2+}$ and that the angle $\mathrm{O} 1-\mathrm{Pb}-\mathrm{O} 2$ is of importance. The bisdirected structure can be obtained with double bonds too. Finally, we know that we need to have an interaction on both sides of the lone pair.

Bisdirected Structures in Biomacromolecules. We now address the question of whether such topology of the lone pair of $\mathrm{Pb}^{2+}$ is possible also in biomacromolecules where $\mathrm{Pb}^{2+}$ sites are asymmetric. We have studied four macromolecules from the PDB that contain $\mathrm{Pb}^{2+}$ ions: $1 \mathrm{QR} 7,{ }^{6} 2 \mathrm{O} 3 \mathrm{C}^{7} 1 \mathrm{NBS},{ }^{8}$ and 3EC8. ${ }^{9}$ No proteins are known that require this ion for its function. Instead, $\mathrm{Pb}^{2+}$ has been added to help the crystallographic structure determination. The crystal structures were used directly for ELF analysis without any geometry optimization. The system has been chosen in a way that a sphere of coordination of $8 \AA$ has been taken: no water molecules have been added. The aim of the first part of this section is to see if a bisdirected structure could exist in an asymmetric environment. Positive findings here were then validated with more advanced studies including QM/MM optimization with saturated $\mathrm{Pb}^{2+}$.

First, we consider the phenylalanine-regulated 3-deoxy-Darabino-heptulosonate-7-phophate synthase (DAHPS; PDB 
code 1QR7). ${ }^{6}$ This enzyme catalyzes the stereospecific condensation of phosphoenolpyruvate and D-erythrose-4phosphate. This reaction gives DAHP and a phosphate group. This is the first step in the biosynthetic pathway, leading to aromatic compounds such as Phe, Tyr, and Trp. ${ }^{10}$

There are four $\mathrm{Pb}^{2+}$ sites in the 1QR7 structure. ELF analysis shows that three of the sites are hemidirected, whereas the fourth is bisdirected. However, as can be seen from Figure 14, the lone pair of the fourth $\mathrm{Pb}^{2+}$ is not perfectly bisdirected; instead, a mixture of a hemi- and bis-directed structure is found. It is hard to make a conclusion on the exact shape of the lone pair of $\mathrm{Pb}$ (II) because the structure is not optimized.

The second enzyme is an apurinic/apyrimidinic endonuclease of zebrafish (PDB code $2 \mathrm{O} 3 \mathrm{C}) .^{7}$ Redox regulation has been shown to play an important role in modulating the DNA binding activity of a number of transcription factors. ${ }^{11}$ This regulation allows a higher affinity between the reduced c-Jun gene product and DNA than between oxidized c-Jun and DNA. $^{2}$ The factor responsible for reducing c-Jun is the apurinic/apyrimidinic endonuclease.

This structure contains three $\mathrm{Pb}^{2+}$ ions. One of the sites is shown in Figure 15. The $\mathrm{Pb}^{2+}$ lone pair is clearly hemidirected.

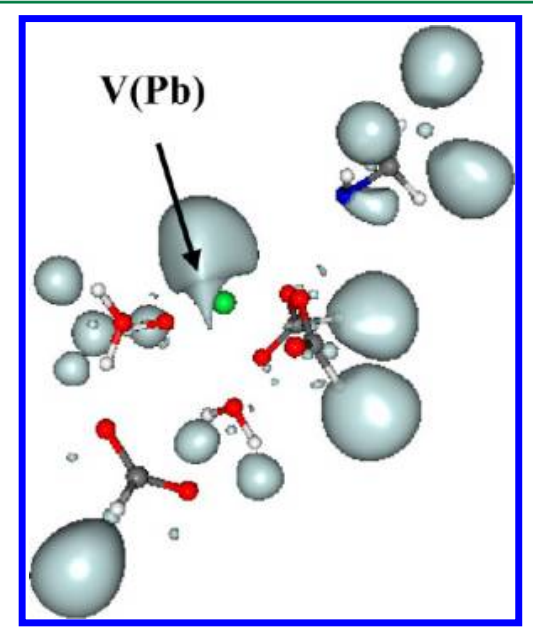

Figure 15. ELF analysis of the third $\mathrm{Pb}$ site in the $2 \mathrm{O} 3 \mathrm{C}$ structure with all crystallographic water molecules. Value of the isosurface, 0.9.

However, we can notice the presence of water molecules around $\mathrm{Pb}^{2+}$. The water structure around metal ions is often subject to rapid change. Therefore, a second ELF analysis was performed also without one of the water molecules (see Figure 16), leading to a bisdirected lone pair. This indicates that there may exist dynamics between hemi- and bisdirected structures.

The third macromolecule is ribonuclease (RNase) P (PDB code $1 \mathrm{NBS}) .{ }^{8} \mathrm{RNase} \mathrm{P}$ is the only endonuclease responsible for the processing the $5^{\prime}$ - end of tRNA by cleaving off a precursor, leading to tRNA maturation. ${ }^{13}$ This polyribonucleotide structure contains $23 \mathrm{~Pb}^{2+}$ sites; some of them have only one or two ligands. Fifteen sites close to the macromolecule were studied by ELF analysis, and bisdirected structures were observed for six of the sites, as is shown in Figure 17. One can see that the six $\mathrm{Pb}^{2+}$ lone pairs are bisdirected despite the nonsymmetric environment.

A problem with the interpretation of these structures is that the structure does not report any water molecules. Therefore, there is a risk that water molecules not visible in this lowresolution structure $(3.15 \AA)$ may change the topology. To test

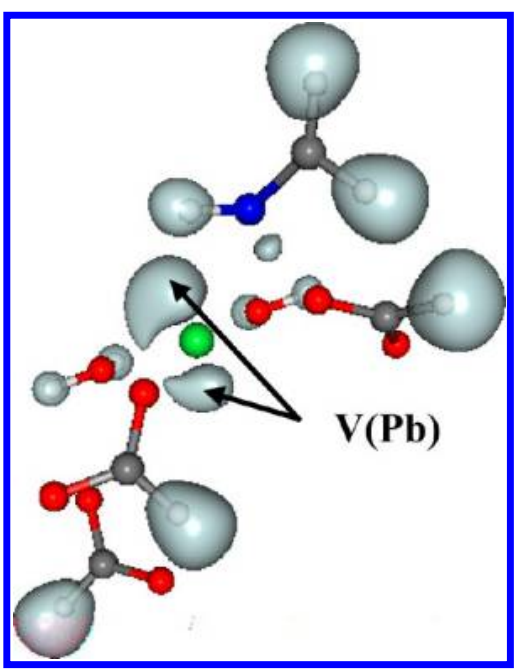

Figure 16. ELF analysis of the third $\mathrm{Pb}$ site in the $2 \mathrm{O} 3 \mathrm{C}$ structure with only one of the three water molecule remaining. Value of the isosurface, 0.9 .

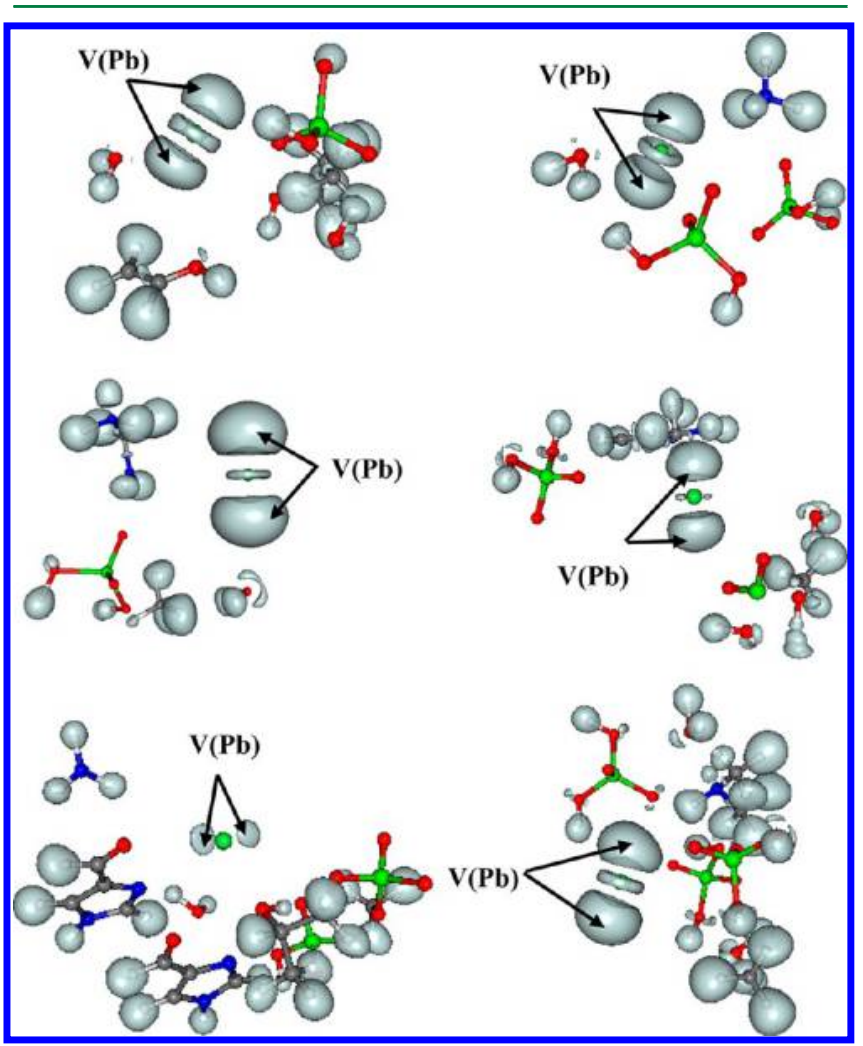

Figure 17. ELF analysis of six of the $\mathrm{Pb}$ sites in the crystal structure of RNase P (1NBS). ${ }^{8}$ The value of the isosurface is 0.9 and shows a bisdirected structure.

this possibility, we added two water molecules to one of the sites in Figure 17 and optimized only the water molecules (giving $\mathrm{Pb}$ six ligands). The optimization was started with the two water molecules on the empty side of $\mathrm{Pb}^{2+}$, opposite the RNA groups, but after the optimization they moved to make hydrogen bonds with the phosphate groups, but also with the lone pair of $\mathrm{Pb}^{2+}$, all ending up on the same side of the $\mathrm{Pb}^{2+}$ ion (Figure 18). Therefore, we can conclude that the presence of a water molecule does not perturb the bisdirected lone pair of $\mathrm{Pb}^{2+}$. 


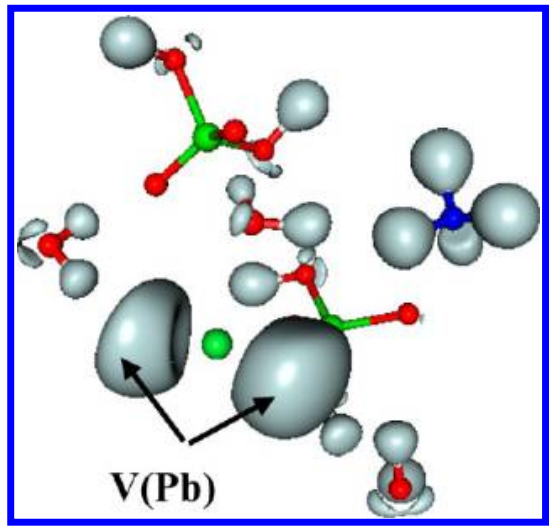

Figure 18. One of the $\mathrm{Pb}$ sites in $1 \mathrm{NBS}$ after the addition of two water molecules: lone pair of $\mathrm{Pb}(\mathrm{II})$ is bisdirected. Value of the isosurface, 0.9 .

Finally, the last protein is an RA domain of FLJ10324 (RADIL), PDB code: 3EC8. ${ }^{9}$ The structure is not covered in any published material at present. This protein contains a single $\mathrm{Pb}^{2+}$ site. In this case, we kept 134 atoms to be sure to get a well-defined environment. An ELF analysis reveals again a bisdirected structure (see Figure 19).

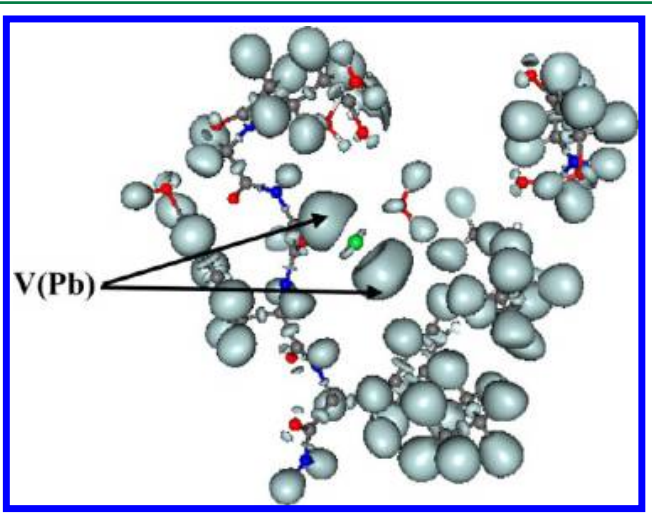

Figure 19. ELF analysis of the $\mathrm{Pb}$ site in the crystal structure 3EC8: $\mathrm{V}(\mathrm{Pb})$ is bisdirected.

With all of these examples, we have demonstrated that a nonsymmetrical environment can support a bisdirected structure. This motivates us to proceed with advanced QM/ MM studies. Therefore, we carried out a QM/MM optimization on the full protein $3 \mathrm{EC} 8$, adding three water molecules to the $\mathrm{Pb}^{2+}$ site. Thereby, $\mathrm{Pb}^{2+}$ (in pink in Figure 20) is surrounded by four water molecules and two oxygens from the protein (one backbone carbonyl group and a Glu carboxyl group, cf. Figure 19).

The ELF analysis after the optimizations (Figure 21) shows that the lone pair of $\mathrm{Pb}^{2+}$ is still bisdirected. This indicates that a bisdirected structure may exist in biological systems.

\section{CONCLUDING REMARKS}

We have studied the occurrence of bisdirected $\mathrm{Pb}^{2+}$ lone pairs in various structures. First, we have studied simple symmetric model complexes to understand when bisdirected lone pairs are encountered. This special bisdirected structure arises by the repulsion of the lone pair of $\mathrm{Pb}^{2+}$ by other lone pairs when the ligands bind in a perpendicular way to the two hemispheres of the bisdirected lone pair. Moreover, double bonds or even

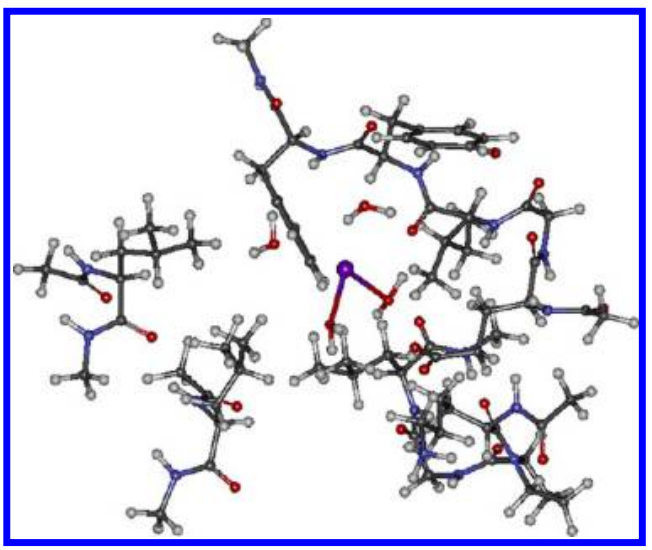

Figure 20. Surrounding of $\mathrm{Pb}^{2+}$ in the $\mathrm{QM} / \mathrm{MM}$ calculation, representing the QM system in 3EC8.

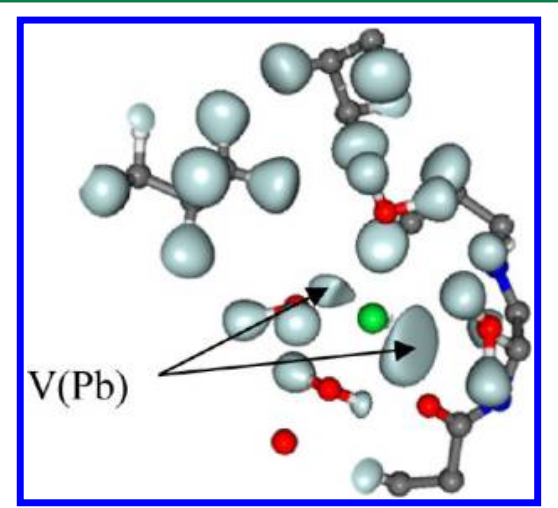

Figure 21. ELF representation of a part of the active site of 3EC8 after $\mathrm{QM} / \mathrm{MM}$ optimization. The lone pair of $\mathrm{Pb}(\mathrm{II})$ is still bisdirected. Value of the isosurface, 0.9 .

hydrogen bonds can induce this topology of the lone pair of $\mathrm{Pb}^{2+}$.

In the second part of this study, we have shown that bisdirected lone pairs can be found in nonsymmetrical $\mathrm{Pb}^{2+}$ sites. Those examples have been done with nonsaturated and nonoptimized systems because the important information was to know if this new topology could exist in an environment organized in a "random" way.

Finally, the QM/MM optimization in a real biological environment saturated in a proper way supports the previous observation. Only at this stage can we think that the bisdirected structure of $\mathrm{Pb}^{2+}$ could exist in some proteins/RNA.

The results are interesting for several reasons. First, they illustrate the need of analysis methods, like ELF, to distinguish between bis-, holo-, or hemidirected structures. Second, they emphasize that the bisdirected topology of $\mathrm{Pb}^{2+}$ can exist in protein/RNA. Future investigations will have to explore the potentially significant difference of hemi-, holo-, and bisdirected structures in biological environments.

\section{METHODS}

All ELF computations have been performed with the TOPMOD package ${ }^{14}$ using electronic densities computed by Gaussian $03^{15}$ at the B3LYP/SDD/6-31++G** level. ${ }^{16}$ The $\mathrm{SDD}$ basis set was used for $\mathrm{Pb}^{2+}$ to treat the relativistic effects.

The QM/MM calculations were carried out with the ComQum program. ${ }^{17,18}$ In this approach, the protein and solvent are split into two subsystems: The QM region (system 
1) contains the most interesting atoms and is relaxed by QM methods. System 2 consists of the rest of the protein and a number of explicitly modeled water molecules. In the QM/MM geometry optimizations, system 2 was fixed at the original (crystallographic) coordinates (because we aimed at reproducing the crystal structure, improving only the structure of the $\mathrm{Pb}$ sites and including a number of water molecules, not discerned in the crystal structure). In the QM calculations, system 1 was represented by a wave function, whereas all the other atoms were represented by an array of partial point charges, one for each atom, taken from the MM libraries. Thereby, the polarization of the QM system by the surroundings is included in a self-consistent manner (electrostatic embedding).

When there is a bond between systems 1 and 2 (a junction), the hydrogen link-atom approach was employed: The QM region is truncated by hydrogen atoms, the positions of which are linearly related to the corresponding carbon atoms in the full system. ${ }^{17,19}$

The QM/MM energy is calculated as

$$
E_{\mathrm{QM} / \mathrm{MM}}=E_{\mathrm{QM} 1+\mathrm{ptch} 2}^{\mathrm{HL}}-E_{\mathrm{MM} 1, \text { noel1 }}^{\mathrm{HL}}+E_{\mathrm{MM} 12, \text { noel1 }}^{\mathrm{CL}}
$$

where $E_{\mathrm{QM} 1+\text { ptch2 }}^{\mathrm{HL}}$ is the $\mathrm{QM}$ energy of the quantum system truncated by hydrogen link atoms (HL) and embedded in the set of point charges, representing system 2 (but excluding the self-energy of the point charges). $E_{\mathrm{MM} \text {,noell }}^{\mathrm{HL}}$ is the MM energy of the QM system, still truncated by HL atoms, but without any electrostatic interactions. Finally, $E_{\mathrm{MM} 123, \text { noel1 }}^{\mathrm{CL}}$ is the classical energy of all atoms with normal atoms at the junctions (carbon link atoms, CL) and with the charges of the quantum system set to zero (to avoid double-counting of the electrostatic interactions). By using this approach, which is similar to the one used in the Oniom method, ${ }^{20}$ errors caused by the truncation of the quantum system should cancel out. Charges on all atoms in the MM system were included (except the CL atoms).

In the QM part, Turbomole ${ }^{21}$ has been used at the DFT level with the functional TPSS ${ }^{22}$ and the def2-SVP basis set for all atoms, which includes a 78-atom relativistic effective core potential for $\mathrm{Pb}^{23}$ The resolution-of-identity (RI) approach was used to accelerate the calculations. ${ }^{24,25}$ The QM system contained 243 atoms. For the MM part, Amber $^{26}$ was used with the 1999 force field. ${ }^{27,28}$ The size of the whole MM system was 5954 atoms.

\section{AUTHOR INFORMATION}

\section{Corresponding Author}

*E-mail: mc.vanseveren@gmail.com.

\section{Notes}

The authors declare no competing financial interest.

\section{ACKNOWLEDGMENTS}

The computations have been performed on the national IDRIS (F. 91403 Orsay, France) and CINES (F. 34097 Montpellier, France) supercomputing centres, and at Lunarc at Lund University. The ELF computations were run at the local CCRE centre at Université Pierre et Marie Curie, Paris 6 (F. 75252 Paris CEDEX 05, France). Support from the French National Research Agency (ANR) on project SATURNIX is acknowledged, as well as financial support from the Swedish science research council (project 2010-5025) and the Swedish Institute.

\section{REFERENCES}

(1) Shimoni-Livny, L.; Glusker, J. P.; Bock, C. W. Inorg. Chem. 1998, $37,1853-1855$.

(2) Mudring, A. In Inorganic Chemistry in Focus III; Meyer, G., Naumann, D., Wesemann, L., Eds.; Wiley-VCH: New York, 2006; pp $15-28$.

(3) Gourlaouen, C.; Parisel, P. Angew. Chem., Int. Ed. 2007, 46, 553556.

(4) van Severen, M.-C.; Piquemal, J.-P.; Parisel, O. Chem. Phys. Lett. 2009, 478, 17-19.

(5) van Severen, M.-C.; Gourlaouen, C.; Parisel, O. J. Comput. Chem. 2009, 31, 185-194.

(6) Shumilin, I. A.; Kretsinger, R. H.; Bauerle, R. H. Struct. Folding Des. 1999, 7, 865-875.

(7) Georgiadis, M. M.; Luo, M.; Gaur, R. K.; Delaplane, S.; Li, X.; Kelley, M. R. Mutat. Res. 2008, 643, 54-63.

(8) Krasilnikov, A. S.; Yang, X.; Pan, T.; Mondragon, A. Nature 2003, 421, 760-764.

(9) Wisniewska, M.; Lehtio, L.; Andersson, J.; Arrowsmith, C. H.; Collins, R.; Dahlgren, L. G.; Edwards, A. M.; Flodin, S.; Flores, A.; Gräslund, S.; Hammarström, M.; Johansson, A.; Johansson, I.; Karlberg, T.; Kotenyova, T.; Moche, M.; Nilsson, M. E.; Nordlund, P.; Nyman, T.; Olesen, K.; Persson, C.; Sagemark, J.; Schüler, H.; Thorsell, A. G.; Tresauges, L.; van den Berg, S.; Weigelt, J.; Welin, M.; Wikström, M.; Berglund, H. To be published, PDB structure 3EC8.

(10) Bentley, R. Crit. Rev. Biochem. Mol. Biol. 1990, 25, 307-384.

(11) (a) Xanthoudakis, S.; Curran, T. EMBO J. 1992, 11, 653-665.

(b) Hanson, S.; Kim, E.; Deppert, W. Oncogene 2005, 24, 1641-1647.

(12) Abate, C.; Patel, L.; Rauscher, F. J. I.; Curran, T. Science 1990, 249, 1157-1161.

(13) (a) Altman, S.; Kirsebom, L. A. The RNA World; Cold Spring Harbor Laboratory Press: Cold Spring Harbor, NY, 1999; Vol. 351. (b) Frank, D. N.; Pace, N. R. Annu. Rev. Biochem. 1998, 67, 153-180.

(14) Noury, X.; Krokidis, F.; Fuster, B.; Silvi, B. Comput. Chem. 1999, 23, 597-604.

(15) Frisch, M. J. et al. Gaussian 03, revision C.02; Gaussian Inc.: Wallingford, CT, 2007.

(16) (a) Lee, C.; Yang, W.; Parr, R. G. Phys. Rev. B 1988, 37, 785789. (b) Becke, A. D. J. Chem. Phys. 1993, 98, 5648-5652. (c) Kuechle, W.; Dolg, M.; Stoll, H.; Preuss, H. Mol. Phys. 1991, 74, 1245-1263. (f) Hay, P. J.; Wadt, W. R. J. Chem. Phys. 1985, 82, 299-310. (d) Schmidt, M. W.; Baldridge, K.; Boatz, J. A.; Elbert, S. T.; Gordon, M. S.; Jensen, J. H.; Koseki, J. S.; Matsunaga, N.; Nguyen, K. A.; Su, S.; Windus, T. L.; Dupuis, M.; Montgomery, J. A., Jr. J. Comput. Chem. 1993, 14, 1347-1363.

(17) Ryde, U. J. Comput.-Aided Mol. Des. 1996, 10, 153-164.

(18) Ryde, U.; Olsson, M. H. M. Int. J. Quantum Chem. 2001, 81, 335-347.

(19) Reuter, N. I.; Dejaegere, A.; Maigret, B.; Karplus, M. J. Phys. Chem. 2000, 104, 1720-1735.

(20) Svensson, M.; Humbel, S.; Froese, R. D. J.; Matsubara, T.; Sieber, S.; Morokuma, K. J. Phys. Chem. 1996, 100, 19357-19363.

(21) Treutler, O.; Ahlrichs, R. J. Chem. Phys. 1995, 102, 346-354.

(22) Tao, J.; Perdew, J. P.; Staroverov, V. N.; Scuseria, G. E. Phys. Rev. Lett. 2003, 91, 146401.

(23) Weigend, F.; Ahlrichs, R. Phys. Chem. Chem. Phys. 2005, 7, 3297-3305.

(24) Eichkorn, K.; Treutler, O.; Öhm, H.; Häser, M.; Ahlrichs, R. Chem. Phys. Lett. 1995, 240, 283-290.

(25) Eichkorn, K.; Weigend, F.; Treutler, O.; Ahlrichs, R. Theor. Chem. Acc. 1997, 97, 119-126.

(26) Case, D. A.; Darden, T. A.; Cheatham, T. E., III; Simmerling, C. L.; Wang, J.; Duke, R. E.; Luo, R.; Crowley, M.; Walker, R. C.; Zhang, W.; Merz, K. M.; Wang, B.; Hayik, S.; Roitberg, A.; Seabra, G.; Kolossvary, I.; Wong, K. F.; Paesani, F.; Vanicek, J.; Wu, X.; Brozell, S. R; Steinbrecher, T.; Gohlke, H.; Yang, L.; Tan, C.; Mongan, J.; Hornak, V.; Cui, G.; Mathews, D. H.; Seetin, M. G.; Sagui, C.; Babin, V.; Kollman, P. A. Amber 10; University of California: San Francisco, 2008. 
(27) Cornell, W. D.; Cieplak, P.; Bayly, C. I.; Gould, I. R.; Merz, K. M.; Ferguson, D. M.; Spellmeyer, D. C.; Fox, T.; Caldwell, J. W.; Kollman, P. A. J. Am. Chem. Soc. 1995, 117, 5179-5197.

(28) Wang, J.; Cieplak, P.; Kollman, P. A. J. Comput. Chem. 2000, 21, $1049-1074$ 